\title{
THE VELOCITY OF BLOOD FLOW IN INFANTS AND YOUNG CHILDREN, DETERMINED BY RADIOACTIVE SODIUM ${ }^{1}$
}

\author{
By JOHN P. HUBBARD, WILLIAM N. PRESTON, AND RALPH A. ROSS \\ (From The Children's Hospital and the Infant's Hospital, and the Department of Pediatrics, \\ Harvard Medical School, Boston, and the Department of Physics, \\ Harvard University, Cambridge)
}

(Received for publication April 10, 1942)

To measure the velocity of blood flow in infants and young children, a completely objective procedure is required. Most of the methods (as for example determining the time elapsed between the injection of a sweet substance (saccharin) or a bitter substance (sodium dehydrocholate) and the arrival on the tongue of its characteristic taste) used for adults need the cooperation of the subject.

The respiratory stimulation caused by potassium cyanide, injected intravenously, was utilized as an objective method by Robb and Weiss (1). We have not tried to apply this method to infants because of the danger in adjusting small doses to small patients. The lethal dose is said to be only about ten times the stimulating dose. Furthermore, the end point would be difficult to evaluate since the infant's respirations would almost certainly be irregular and disturbed by crying and emotional excitement.

A satisfactory method for infants calls for a test material which can be accurately and objectively measured in small amounts and which, in the doses. used, is completely harmless. Radioactive sodium appeared to satisfy these requirements.

The principle of using a radioactive substance was developed by Blumgart and Weiss (2), who injected the active deposit of radon into the antecubital vein of one arm, detecting its arrival in the other arm by a properly shielded cloud chamber. The active deposit consists of radium $B$ and its products in equilibrium. It decays with a half-life of 26 minutes. The dose which they used, usually about 5 millicuries, was so small as to present no immediate danger. However, the residue is radium $\mathrm{D}$, a radioactive isotope of lead, with the very long half-life of 22 years. Although the activity of radium $D$, resulting from the disintegration of 5 millicuries of active deposit is very

1 Read before the Society for Pediatric Research at Atlantic City, New Jersey, May 7, 1941. small, about 0.025 microcuries, the fact that lead isotopes are concentrated in bones and are eliminated with difficulty makes doubtful the wisdom of injecting into infants a substance which might over a period of years have a deleterious effect on bone growth.

Radioactive sodium on the other hand has a half-life of 15 hours. After disintegration it leaves a normal, inactive atom and there can be no possible ill effects years later. The disadvantages of radioactive sodium as compared with the active deposit of radon are (1) it must be produced by cyclotron bombardment and is therefore not generally available, (2) its longer half-life means that the initial dose in microcurie hours is larger, (3) circulation rate measurements can be repeated in the same individual only after a couple of days have passed, as opposed to 2 hours with active deposit, and (4) its gamma rays are so penetrating as to present some problems in adequate shielding of the detector. With these limitations, however, the method is feasible, and has given results which appear reliable.

\section{METHODS}

The test material was prepared in the Harvard cyclotron by bombarding a layer of c.p. sodium metal $1 \mathrm{~mm}$. thick for one hour with 11.5 million electron volt deuterons (charged nuclei of "heavy" hydrogen) with a beam strength of 10 microamperes. About 1 gram of the activated sodium metal was dissolved in a paraffin-lined beaker in $100 \mathrm{cc}$. of distilled water under $\mathrm{CO}_{2}$ gas. After filtering, it was made slightly acid with $5 \mathrm{~N} \mathrm{HCl}$, boiled to expel $\mathrm{CO}_{2}$ and to precipitate any silicates, again filtered, and finally neutralized by addition of dilute $\mathrm{NaOH}$ or $\mathrm{HCl}$ with bromthymol-blue indicator. It was made up to a concentration of 2 per cent to 5 per cent sodium chloride. The test dose was then contained in less than 1 cc., usually 0.1 to $0.5 \mathrm{cc}$. Such small amounts of hypertonic solution could not be expected to have any effect on the velocity of blood flow.

The radioactivity of the resulting solution was measured by comparison with the gamma-ray activity of a 
known radium sample using a Geiger counter. It was further checked by determining the counting rate with a counter subtending a known solid angle and using a calculated gamma-ray efficiency factor.

The test dose was calculated on the basis of the subject's weight and varied between 2 and 5 microcuries per kilogram of body weight. Since the radiosodium is distributed rapidly throughout the body, there is no danger of large localized irradiation. The total dose was well within a conservative limit of safety when compared to estimated $x$-ray tolerance. In order to establish the innocuousness of this dose, preliminary tests were done on volunteer adults. Total and differential blood counts were taken before and at intervals following the injection. The blood counts, which may be considered the most sensitive indication of measurable effect from irradiation (3) showed no significant changes. Much larger doses of radioactive sodium have been given therapeutically to adults with leukemia. Hamilton and Stone (4) have given up to 54 millicuries without resulting blood changes, whereas the dose used here for an adult weighing 80 kilograms would be, at 4 microcuries per kilogram, 320 microcuries or 0.32 millicuries. All of the infants and most of the older children who were tested were hospitalized patients, so that it was possible to observe them closely following the procedure. No effects referable to the procedure were noted in the clinical condition, the blood counts, or urine analyses.

In performing the test, the radioactive sodium chloride solution was first sterilized by boiling and then injected into one arm while the opposite hand was held close to a Geiger counter, shielded by several inches of lead. From the Geiger counter a Nehr-Harper extinguishing circuit with one stage of voltage amplification, power amplifier, and pulse-lengthening circuit was arranged so as to record the arrival of the radioactive material on a waxed tape running at constant speed.

The Geiger counter has unfortunately a certain "background" counting rate, due to cosmic rays and radioactive materials in the walls of the building, etc. In each case before the injection was made, the background rate which averaged about 1 count each 2 seconds was measured over a period of 1 minute. The intravenous injection was then made by an assistant and the time of the injection marked on the recording tape by means of a circuit from a telegraph key. The tape was allowed to run at its constant rate until a few moments after the arrival in the hand of the radioactive material, which was signaled by the rapid increase in the counting rate.

From the record on the tape, spot graphs were made (Figure 1), each recorded count being represented by a dot in the proper position along the time axis. Each successive dot was put one coordinate unit above the preceding dot so that the ordinate equaled the total number of counts up to any given time. The slope of a straight line drawn through these dots represents the counting rate itself. The arrival of the radioactive material is thus indicated by a sharp rise in the slope. The time interval in seconds between the injection and this rise in slope then denotes the circulation rate.

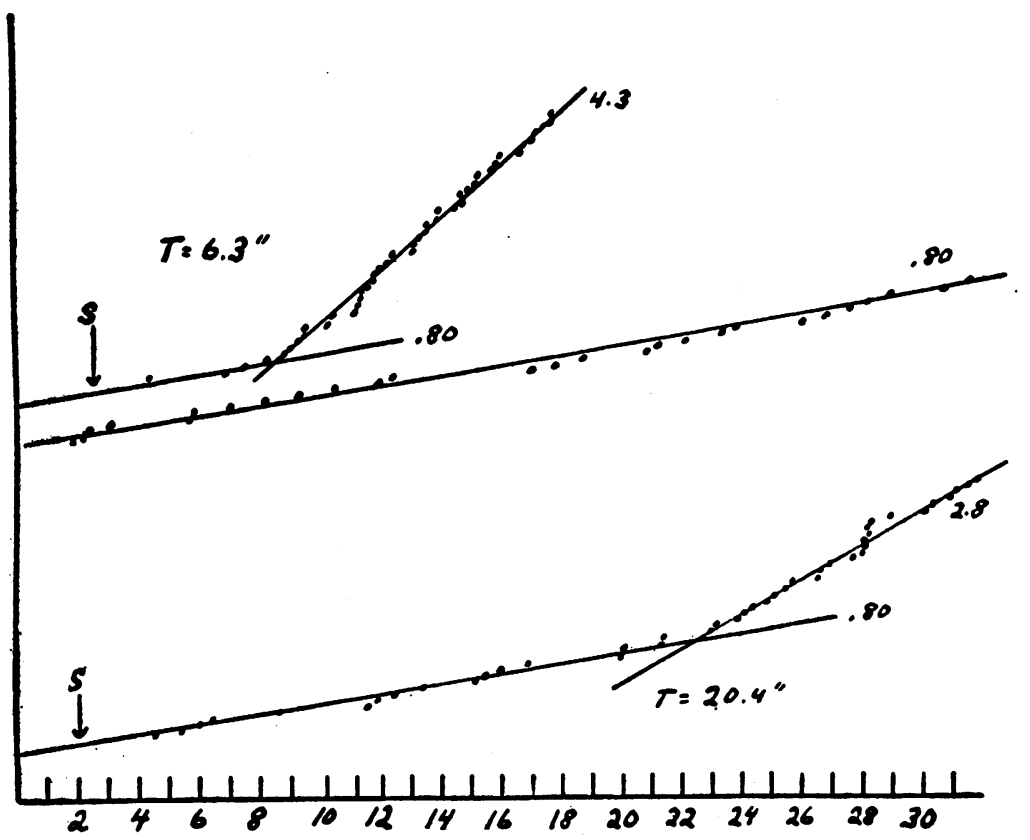

Fig. 1. Spot Graph of 2 Tests Showing Circulation Rate as the Time in Seconds Between the Injection (S) and the Sudden Increase in the Frequency of the Counts Denoted as an Abrupt Rise in Slope of a Line Drawn Through the Dots 
Fluctuations of the background unfortunately set a limit to the accuracy of the test. However, observations of a large number of spot graphs have led us to believe that the error is seldom more than \pm 1 second.

\section{RESULTS IN CHILDREN 2 TO 12 YEARS}

In Table $I$ are shown the results in 22 children between the ages of 2 and 12 years who had a variety of medical diagnoses, both cardiac and non-cardiac. Only 1 (No. 18) had any condition which might have been expected to alter the speed of circulation. This child had rheumatic heart disease and congestive failure which might have caused a slow rate but actually the rate was rather fast.

Radioactive sodium and saccharin were usually injected simultaneously so that one method could serve as a check against the other. This was done by mixing the measured dose of the activated salt solution with $1 \frac{1 / 2}{1}$ to $2 \mathrm{cc}$. of a sterile saccharin solution, made by adding 20 grams of saccharin to $25 \mathrm{cc}$. of distilled water. For the smaller children $1 \frac{1}{2} \mathrm{cc}$. was used and $2 \mathrm{cc}$. for the larger ones. As seen in Table $I$ there is good correlation between the saccharin and sodium time in some cases and very poor correlation in others. Where the correlation was poor, it was our impression that the sodium time represented the truer value. It is sometimes difficult for an apprehensive child, even if eager to cooperate, to time a taste end-point accurately. Occasionally a child would be too eager and speak too soon, or on the other hand he might be slow to appreciate the taste. These are single determinations; if the child had been accustomed to the procedure by previous tests, better correlation might have resulted.

In general, the circulation rates in this group correspond with those of older children previously reported. Blumgart \& Weiss (2), in their original work with the active deposit of radon, tested the rates of 22 children and young adults ranging in age from 15 to 29 years. The results averaged 17 seconds, varying from 12 to 23 seconds. Tarr, Oppenheimer, and Sager (5) measured the arm to tongue time with decholin in 15 children between the ages of 10 and 14 years. In 8 of these children with normal or well-compensated rheumatic heart disease, the rate ranged from 10 to 17.5 seconds. Averbuck and Friedman (6) de-

TABLE I

Velocity of blood flow in children aged 2 to 12 years

\begin{tabular}{|c|c|c|c|c|c|c|}
\hline \multirow{2}{*}{$\underset{\text { ber }}{\text { Num- }}$} & \multirow{2}{*}{ Diagnosis } & \multirow[b]{2}{*}{ Age } & \multirow{2}{*}{ Weight } & \multirow{2}{*}{ Height } & \multicolumn{2}{|c|}{ Circulation time } \\
\hline & & & & & Saccharin & $\begin{array}{c}\text { Radioactive } \\
\text { sodium }\end{array}$ \\
\hline $\begin{array}{r}1 \\
2 \\
3 \\
4 \\
5 \\
6 \\
7 \\
8 \\
9 \\
10 \\
11 \\
12 \\
13 \\
14 \\
15 \\
16 \\
17 \\
18 \\
19 \\
20 \\
21\end{array}$ & $\begin{array}{l}\text { Patent ductus arteriosus } \\
\text { Rheumatic fever-normal heart } \\
\text { Rheumatic fever-normal heart } \\
\text { Rheumatic fever-suspect } \\
\text { "Grippe" } \\
\text { Nephritis } \\
\text { Splenomegaly } \\
\text { Celiac disease } \\
\text { Ulcerative colitis } \\
\text { Patent ductus arteriosus } \\
\text { Chorea } \\
\text { Rheumatic heart disease } \\
\text { Rheumatic fever-normal heart } \\
\text { Rheumatic heart disease } \\
\text { Rheumatic heart disease } \\
\text { Rheumatic heart disease } \\
\text { Rheumatic heart disease-Rheumatic fever } \\
\text { Rheumatic heart disease-decompensated } \\
\text { Rheumatic heart disease } \\
\text { Pyelonephritis } \\
\text { Pyelonephritis }\end{array}$ & $\begin{array}{c}\text { years } \\
11 \\
9 \\
11 \\
10 \\
9 \\
10 \\
10 \\
5 \\
11 \\
8 \\
9 \\
8 \\
11 \\
7 \\
11 \\
12 \\
11 \\
9 \\
6 \\
3 \\
3\end{array}$ & $\begin{array}{c}\text { pounds } \\
84 \\
61 \\
61 \\
66 \\
68 \\
70 \\
70 \\
29 \\
77 \\
43 \\
50 \\
52 \\
92 \\
45 \\
75 \\
75 \\
70 \\
43 \\
35 \\
30 \\
28\end{array}$ & $\begin{array}{l}52 \\
57 \\
35 \\
55 \\
46 \\
\\
60 \\
44 \\
56 \\
60 \\
55 \\
\\
37 \\
37\end{array}$ & $\begin{array}{r}\text { seconds } \\
9 \\
8 \\
? 15 \\
5 \\
9 \\
6 \\
13 \\
7 \\
9 \\
? 14 \\
3 \\
? \\
12 \\
12 \\
11 \\
16 \\
?\end{array}$ & $\begin{array}{l}\text { seconds } \\
10 \\
14 \\
16( \pm 2)^{*} \\
11 \\
8 \\
17(-2)^{*} \\
14( \pm 1.5)^{*} \\
8 \\
14 \\
7 \\
9 \\
6 \\
10 \\
13 \\
17 \\
11 \\
13 \\
5 \\
10 \\
7 \\
8\end{array}$ \\
\hline
\end{tabular}

Range 5 to 17 seconds

Average 11 seconds

* Possible correction shown in parentheses. All other determinations have a possible error of less than \pm 1 second. 
TABLE II

Velocity of blood flow in infants aged 0 to 2 years

\begin{tabular}{|c|c|c|c|c|c|}
\hline$\underset{\text { ber }}{\text { Num- }}$ & Diagnosis & Age & Weight & Height & $\begin{array}{c}\text { Circulation time } \\
\text { radioactive sodium }\end{array}$ \\
\hline $\begin{array}{r}1 \\
2 \\
3 \\
4 \\
5 \\
6 \\
7 \\
8 \\
9 \\
10 \\
11 \\
12 \\
13 \\
14\end{array}$ & $\begin{array}{l}\text { Convalescent pneumonia } \\
\text { Convalescent pneumonia-Pyelonephritis } \\
\text { Convalescent pneumonia-Pyelonephritis (Same as No. 2, one } \\
\text { week later) } \\
\text { Convalescent pneumonia } \\
\text { Chronic nutritional disorder } \\
\text { Celiac disease } \\
\text { Nutritional anemia } \\
\text { Chronic nutritional disorder } \\
\text { ?Scurvy. } \\
\text { Upper respiratory infection } \\
\text { Convalescent pneumonia } \\
\text { Convalescent pneumonia } \\
\text { Pyelonephritis } \\
\text { Cretinism }\end{array}$ & $\begin{array}{l}6 \text { weeks } \\
6 \text { weeks } \\
7 \text { weeks } \\
4 \text { months } \\
9 \text { months } \\
20 \text { months } \\
15 \text { months } \\
16 \text { months } \\
18 \text { months } \\
22 \text { months } \\
13 \text { months } \\
13 \text { months } \\
6 \text { months } \\
6 \text { months }\end{array}$ & $\begin{array}{c}\text { pounds } \\
7 \\
7 \\
7 \\
10 \\
9 \\
16 \\
19 \\
16 \\
19 \\
24 \\
19 \\
19 \\
18 \\
11\end{array}$ & $\begin{array}{c}\text { inches } \\
21 \\
22 \\
22 \\
\\
23 \\
22 \\
30 \\
\\
28 \\
32 \\
\\
30 \\
30 \\
28 \\
23\end{array}$ & $\begin{array}{c}\text { seconds } \\
6 \\
3^{*} \\
6 \\
9^{*} \\
6^{*} \\
12 \\
5 \\
7 \\
4 \\
11 \\
10 \\
6 \\
10 \\
6\end{array}$ \\
\hline
\end{tabular}

Range 3 to 12 seconds

Average 7 seconds

* Injection into ante-cubital vein (all others into small vein on back of hand).

termined the rates of 100 normal children, from 8 to 16 years, using saccharin. The average time was 8.6 seconds with a range of 5 to 13.5 seconds.

In the present group of 22 children between 2 and 12 years, the rates determined by radioactive sodium average 11 seconds, with a range of 5 to 17 seconds.

\section{RESULTS IN INFANTS YOUNGER THAN 2 YEARS}

In infants, there are technical difficulties which complicate the procedure. In the first place, the ability to make a clean rapid intravenous injection is obviously essential and often difficult. Usually a small vein on the back of the hand was selected for the injection. Care had to be taken not to introduce any radioactive saline into the circulation prematurely, and then to inject the whole dose as quickly as possible.

Secondly, the infants were, as could be expected, actively resenting being held in place and being pricked with a needle. Since there was no satisfactory way of avoiding the factors of struggling and crying, we attempted to determine how much influence these factors may have had. In 2 normal adults, rates were determined by the saccharin method, first at rest, then with glottis closed after a deep inspiration, and finally after exercise (Table III). The second step in this experiment was an attempt to simulate the physiology of crying by increasing the intrathoracic
TABLE III

Circulation rates in 2 normal adults at rest, with increased intrathoracic pressure, and after exercise

\begin{tabular}{lcc}
\hline \hline & J.P.H. & R.A.R. \\
\hline Resting & 16 seconds & 18 seconds \\
$\begin{array}{l}\text { Deep breath } \\
\text { (Glottis closed) }\end{array}$ & 22 seconds & 23 seconds \\
After exercise & 14 seconds & 12 seconds
\end{tabular}

pressure. This tends to slow the rate and to counteract, therefore, the effect of the exercise. Cannon, Lucia, and Benson (7) have also shown that the increased-rate resulting from exercise is not very appreciable. It seems reasonable to conclude, therefore, that the effect of struggling and emotional excitement was slight.

In the group of infants, there were none who had any condition which would be expected to influence the circulation rate. As shown in Table II, there were 14 infants between 6 weeks and 22 months of age. Their sodium rates varied between 3 and 11 seconds, with an average of 7 seconds.

\section{SUM MARY}

The velocity of the blood flow in young infants and children has been measured by determining the time elapsed between the injection of radioactive sodium into one arm and its arrival in the 
opposite hand. The latter has been signaled by a Geiger counter.

By this method the rate in 22 children between 2 and 12 years was found to average 11 seconds, with a range of 5 to 17 seconds. The rate of 14 infants between 6 weeks and 22 months of age averaged 7 seconds, with a range of 3 to 12 seconds.

\section{BIBLIOGRAPHY}

1. Robb, G. P., and Weiss, S., A method for measurement of velocity of pulmonary and peripheral venous blood flow in man. Am. Heart J., 1933, 8,650 .
2. Blumgart, H. L., and Weiss, S., Studies on the velocity of blood flow. J. Clin. Invest., 1927, 4, 15.

3. Warren, S.: Personal communication.

4. Hamilton, J. G., and Stone, R. S., The intravenous and intraduodenal administration of radioactive sodium. Radiology, 1937, 28, 178.

5. Tarr, L., Oppenheimer, B. S., and Sager, R. V., The circulation time in various clinical conditions determined by the use of sodium dehydrocholate. Am. Heart J., 1933, 8, 766.

6. Averbuck, S. H., and Friedman, W., Circulation time in normal children. Am. J. Dis. Child., 1935, 49, 361.

7. Cannon, E. F., Lucia, S. P., and Benson, E. H., Circulation time under conditions of work and rest in subjects with normal and abnormal hearts. Proc. Soc. Exper. Biol. and Med., 1939, 42, 237. 